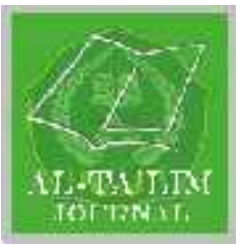

AL-TA'LIM JOURNAL, 23 (2), 2016, (175-182)

(Print ISSN 1410-7546 Online ISSN 2355-7893)

Available online at http://journal.tarbiyahiainib.ac.id/index.php/attalim

\title{
الطلاب شخصية تربية في ودورها الإسلامية التربية
}

Received: $17^{\text {th }}$ December 2015; Revised:18 ${ }^{\text {th }}$ January 2016; Accepted: $19^{\text {th }}$ July 2016

Permalink/DOI: http://dx.doi.org/10.15548/jt.v23i2.165

\section{Rumadani Sagala}

Institut Agama Islam Negeri Lampung, Indonesia

e-mail: rumadanisagala@yahoo.com

\begin{abstract}
Personality is a compacted word that easy to say, but it is difficult to be realized. Etymologically, the personality comes from the Latin language which means persona. This word refers to a mask used by actors in classical drama. Personality is also becomes the reflection of attitude and action of a person or a nation which sets its uniqueness from people or other nations. In Islamic educational context, it is as characteristic and Islamic identity. Thus, the religion that carries out the mandate will enhance the personality and noble character. Personality can be fully determined when the research has done and met the scientific criteria. Therefore, the personality can be taught in schools, introduced to the students through their habituation, principles and ethics. In al-Qur'an, it has been mentioned the terms of formation and development of the human personality, some influential factors and the ways to solve the problems. Muslims as well as believers from the perspective of Islam are those who always train their heart and are not easily get angry but they should be generous, obey Allah, SWT.
\end{abstract}

$$
\begin{aligned}
& \text { مستخلص البحث : الشخصية هي الكلمة الموجزة، سهل قولها، ولكن صَعْب تحقيقها. } \\
& \text { فالشخصية في اللغة مشتقة من اللغة اللاتينية وهي شخص. هذه الكلمة تشير إلى قناع } \\
& \text { أو أقنعة التيترتديها الجهات الفاعلة في الدراما الكلاسيكية. الشخصية هي الطبيعة } \\
& \text { الأساسية التي تتجلى في مواقف وأفعال الشخص أو الشعب التي تميزهم عن غيرهم من }
\end{aligned}
$$

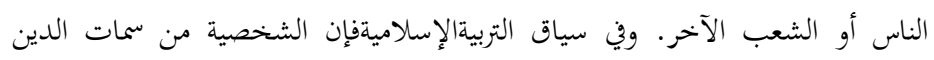

$$
\begin{aligned}
& \text { الإسلامي وهويته في آن واحد، وهو منذ بجيئه يحث علتعزيز الشخصية وإتمام الأخلاق }
\end{aligned}
$$

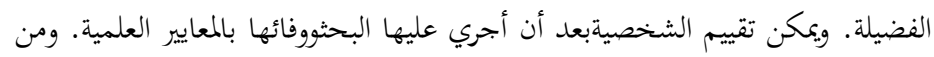

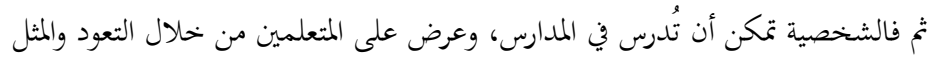

$$
\begin{aligned}
& \text { والأخلاق. في القرآن كثيرا ما يذكر من حيث تشكيل وتطوير للشخصية الإنسانية، }
\end{aligned}
$$

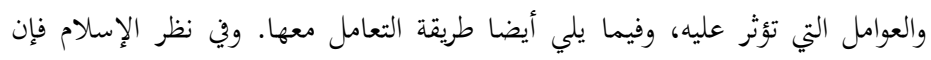

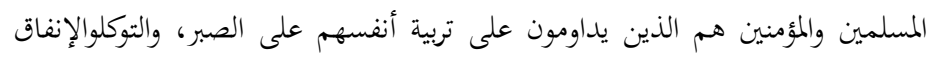

$$
\begin{aligned}
& \text { والعبادة، وكذلك الحفظ علسالأفعالوالتصرفات عن ميلهمالشهوات الحيوانية. }
\end{aligned}
$$

Keywords: Tarbiyah Islamiyah, character education, student.

How to Cite: Sagala, R. (2016). شخصية تربية ودورها الإسلامية التربية . Al-Ta Lim Journal, 23(2). doi:http://dx.doi.org/10.15548/jt.v23i2.165 


\section{خلفية المشكلة}

في عصر السوق الحرة اليوم، مع التقدم في تكنولوجيا

الاتصالات وتكنولوجيا الهندسة، أنتجت ثقافة رقمنة المعيشة المعاف

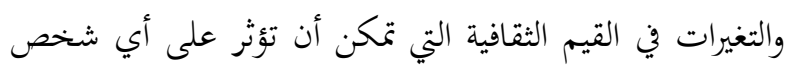
الذي لميبال بمسائل نُمُّ شخصيته.

من خلال السوق الحرة، يمكن أن تكون العملة داخلة وخارجة بلد ما من غير أي سيطرة. دور الدولة يصبح ضعيفا

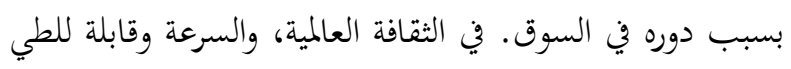
متعددة في الكلمة في عملية العمل. ومع ذلك، والثقافة العالمية ليست شيئا لا مفر منه. وهذا هو، الثقافة العالمية، وظروف بهن جديدة وثقافة جديدة ليست مثل زلزال، ولكن يرجع ذلك إلى لئل

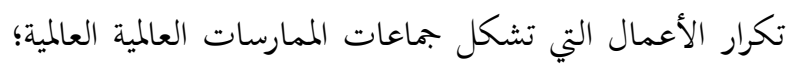

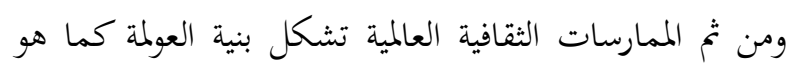
الحال اليوم

ثم ماذا يمكن أن يقدّم التعليم الديني الإسلامي لتوقّع

تأثير الثقافة العالمية؟ في هذا السياق، يمكن أن يكون التعليم الديني الإسلامي واحدا من القيم الأساسية (الأساسية) للجهود

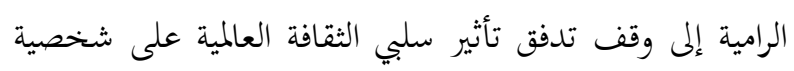
المسلم، وخاصة للمتعلمين المسلمين.

تمكن المحاولة إلى إنشاء شخصية قوية من خلال التربية الإسلامية في المدارس لإبراز الضوء على الجانب العاء العاطفي من التعليم، وليس التركيز المفرط على الجوانب المعرفية. ، أن E. Mulyasa) تذكر الكاتب عبارة البروفيسور

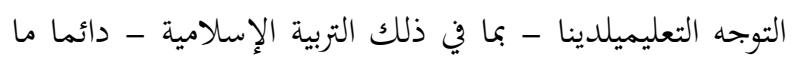
تركز على الجوانب المعرفية، وكان على مستوى منخفض من الجنان

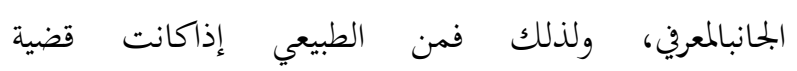
الشخصيةوالأخلاق وطابع المعلمين والطلاب دائما بحاهلها

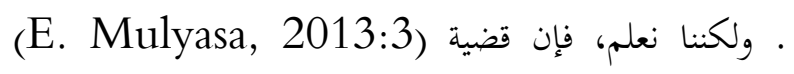
الشخصية هي ما بتعل إندونيسيا كدولة التيتواجه أسوأ أزمة

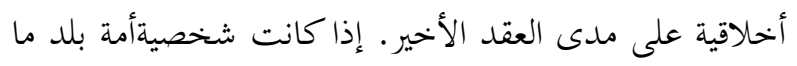

قوية ستنتهى أزمات تلك البلد بسهولة، بما في ذلك أزمة

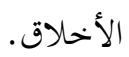

إن تشيكل شخصية المتعلمين القوية من خلال التربية

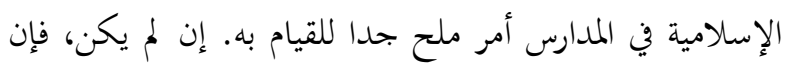
التنيجة سوف تكون المؤسسة التعليمية -خحاصة المدرسة- ملحسيح مستمرة في تجاهل الجوانب الأخرى منالحياة ، مثل أهمية تعزيز الشخصية، لبناء العلاقات مع الآخرين، والحاجة للأنشطة

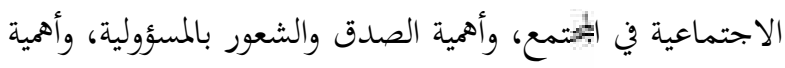

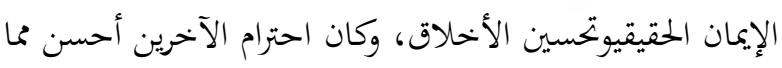

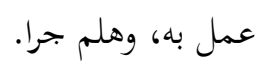

التعريف على شخصية الأمة من جديد النظرية في الشخصية لا يمكن فصلها عن النظرية التي

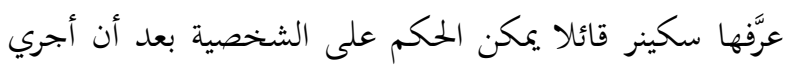

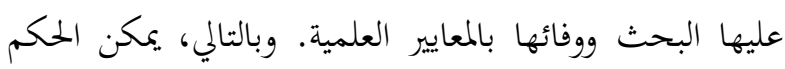

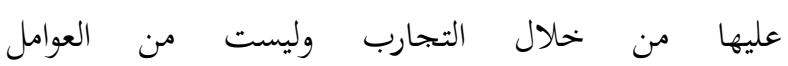
الخارجية. (Alex Sobur, 2013: 309)

الشخصية هي الكلمة الموجزة، سهل القول، ولكن صعب تحقيقها.فالشخصية في اللغة مشتقة من اللغة اللاتينية

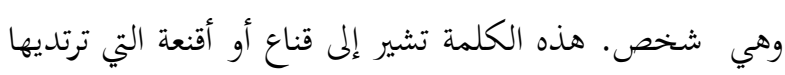
الجهات الفاعلة في الدراما الكلاسيكية. Chalplin, 2011: 362) وي الاصطلاح، عرَّها كثير من الخبراء. وقال وليام

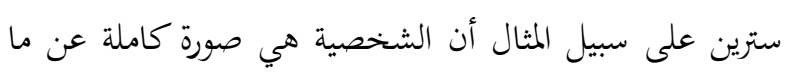
كانت في الشخص، موجهة إلى غرض معين بحرية. قال موريسون أن الشخصية هي بحموعة ما يمكن أن يمقّقها الفرد لإظهار نتائج ثقافية من خلال مراقبة الجتماعية. وفي هذا الإطار، يرى غوستاف يونغ أن الشخصية عبارة عن نإن

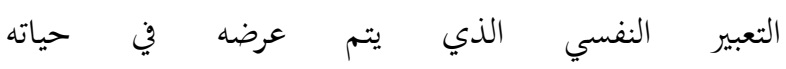
الشخصي. Jalaludin, 2001: 172 
وفقا لمعجم اللغة الإندونيسية في الطبعة الثالثة، يتم

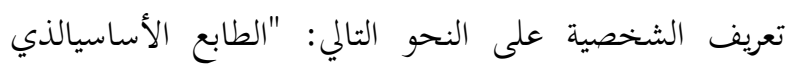

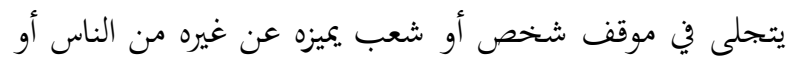

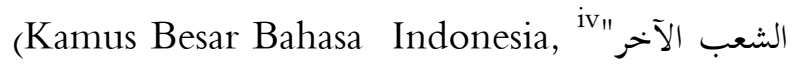
2003.أما الهوية الوطنية هي "الخصائص أو الطابع

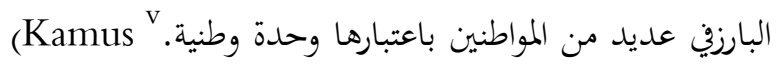
Besar Bahasa Indonesia, 2003: 895)

وكل خبير من الخبراء لهم التعريفات الخاصة بكم عن مأن الشخصية. وفي رأيأليكس صابور، بالإشارة إلى رأي ألبورت،

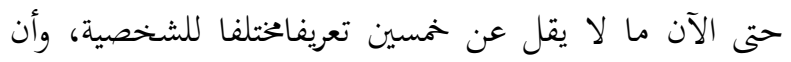

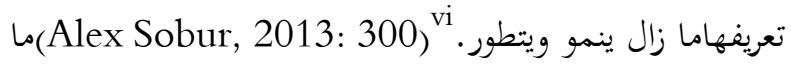

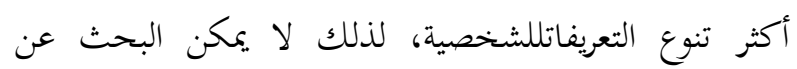
تعريف مقبول لدى الجميع.

\section{التربية الإسلامية: محاولة تكوين وتربية الشخصية}

لهذا السبب، فيمكن أن تصاغ الشخصية بمثابة تعبير

عن موقف فطري، وهي سمة بارزة على خصائص الشخص الذي يصبح هويته

إن شخصية الوطن هي الهوية للوطن. ومع ذلك، فإن

هذه الصيغة شائعة جدا. لذلك، لتسهيل الدراسة، أن تتركز الشخصية في هذه المقالة على البيانات التي كثرت إشاريتافي القرآن أو المعلومات الصادرة عن الأنبياء والرسلفي بيان عن المني

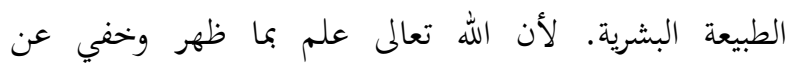

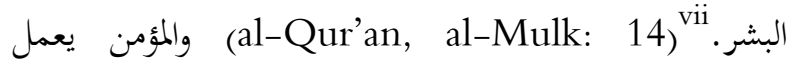
بشخصيته للتوكل على الله تعالى. al-Qur'an, alMulk: 14)

وصف القرآن الكريم آيات عديدة فيما يتعلق بخلق

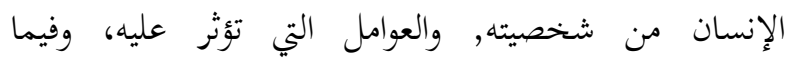
يتعلقبكيفية التعامل معه. وفي نظر الإسلامفالمسلمون والمؤمنون

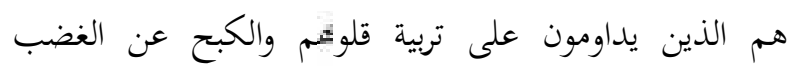

(الصبر)، والصدقة، والعبادة للهوالحفظ على شهوته (انحراف

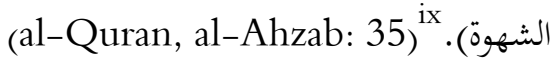

هذا هو المفتاح لشروط مفهوم الشخصية في الإسلام.

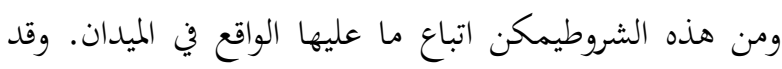
لوحظ العديد من الدراسات أن من بين التعاليم المتعلقة

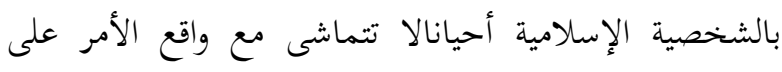
شخصية المسلمين. طوال هذه الفترة كان بعض الباحثين

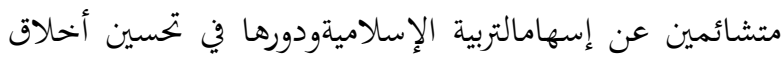

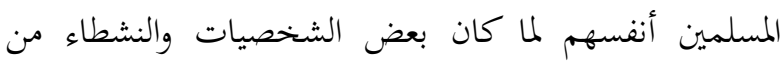
المنظمات الإسلامية متورطين في قضايا الفساد المالي.

الإسلام، بوصفه تعاليم، جعلت دائما التركيز على

خلق، وموقف وسلوك كل هذا أن تكونسمة بارزة في الختمع. فضلا عن أنواع أخرى من العبادة والضبط على الأهواء حتى لا هل الح

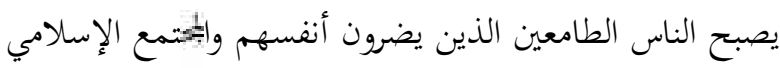

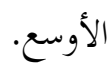

في سياق التربية الإسلامية المدروسة من مرحلة روضة

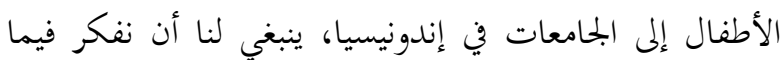
قدمتهالتربية الإسلامية لتحسين الجيل الحالي والأجيال المقبلة.

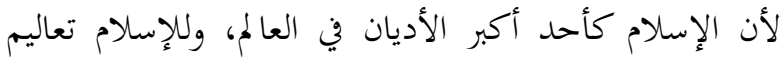
شاملة بشأن قضاياالشخصية، وقد عُرضت تلك الك التهر التعاليم الإسلامية للشباب منذ فترة طويلة. وقد أبزز العلماء السابقون على كيفية تدريس مفهوم الشخصية من خلال المواد الدراسية

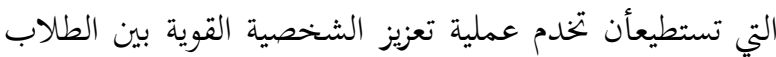

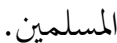
إن عملية تكوين الشخصية في التربية الإسلامية تنبغي

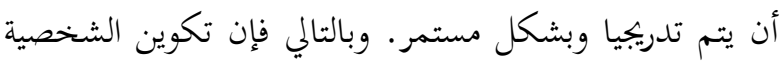
هو عبارة عن سلسلة نشاط متصلومترابطبعضه البعض. ما زالت المدارس تدعو الطلاب للتأمّلفي التعاليم الدينية من أجل بناء شخصية وسلوك محمود، بمعنى أن تكون 
لديهمنزاهة نفسية وشخصية قوية ومقاومة لمختلف أنواع المغريات السلبية الصادرة من الجتمع، باعتبارهم إنسانا كاملا ناشئامتماشيا مع روح فلسفية التي ورثها الإسلام وقد أكدها

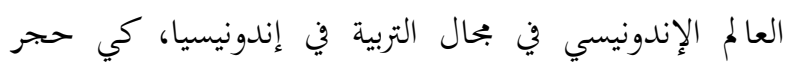

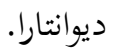

أصبح مفهوم الشخصية في الإسلام ضرورة أن تنفذ

في المدارس كمحاولة توفير الوسيلة لحل ضعف الهوية الوطنية بسبب التحديات الآتية من الداخل والخارج. وبالتالي فمجرد

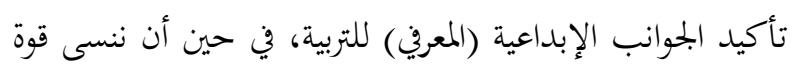

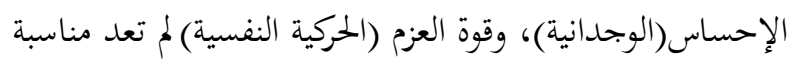

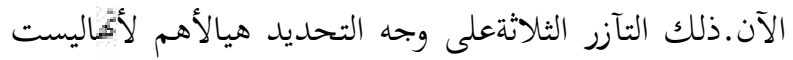
من منتج منفصل ولكنهاوحدة الترابط في الدعم والتعزيز لبعضها

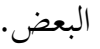

تكوين الشخصية القوية يجب أن تبدأ من توجيه

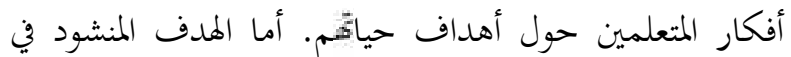
تكوينالشخصية، على سبيل المثال، تكوينها للإنضباط بالوقت،

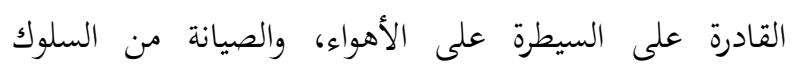
المنحرف، وتوجيههانحو سلوك محمودوهادف، ودراسة التغيرات في أنماط الحياة، وتنمية التفاهم الذاتي، والقيم الذاتية، والإحتياجات الذاتية، من أجل مساعدة الآخرين بغرض أنماطهاه

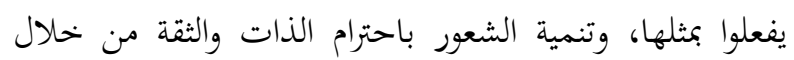
جانب التأييد وجانب المسؤولية المتبادلة.

تشير التربية في الإسلام إلى هدف الحياة البشرية,وأن هدفحياته في هذه الدنيا هو العبادةإلى لله تعالى، والتسليمالتام.

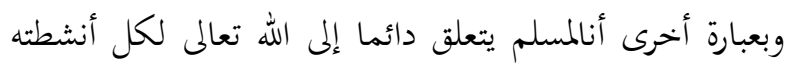
ولا يتجاوز عن حدوده

التربية الإسلامية هو النظام الذي يمكن أن يوفر

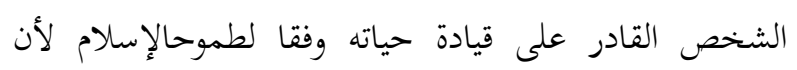
القيم الإسلامية انصهرت في شخصية المرء عند حياة البختمع

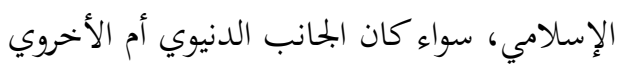

تكوينالشخصية في التربية الإسلامية تشمل المواقف

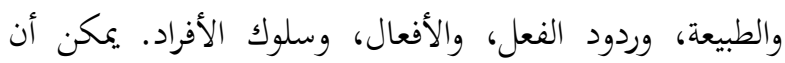
يستمر هذا التكوين مع تنمية الذات التي تم تعيينها نسبيا في الشخص الذي اتبعه ببعض الأساليب، وهي مناقشة أنماط الشخصية، ونمط نضج الوعي الديني ، ونمطعن المؤمنين

والنظر إلى حالة التعليم في إندونيسيا حاليا، لم يكن قادرا على جلب الأفراد المسلمين المستقلينوشخصية جيدة حسب رغبة المعيارية لم يكن مترابطوالذي لا يزال غير واضح المعالم للغاية. لذا، فقد حان الوقت للمدارس أن تحدد أولويات

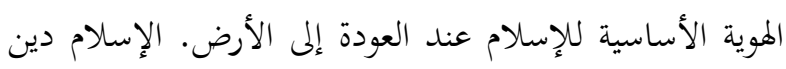
متممللأخلاق ، ويعلم شخصية جيدة ونبيلة الآن يجب أن تكون هناك أولويات في المدارس نحو

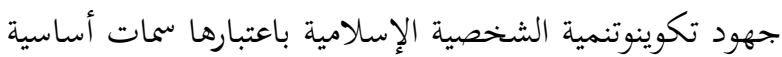
للتعاليم الإسلامية. لا بد من معالجة الفجوة بين المعيارية

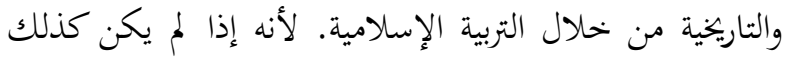
سيزداد أناس ضعاف النفس مثل سارقي أموال الآخرين والبخرمينوأناس غيرجدير بالثقة.

وتحقيقا لمذه الغاية، فإن تكوين الشخصيةوتنميتها في التربية الإسلامية يجب أن تتحقق وفقا للقرآن والسنة وباعتبارها الهوية الإسلامية، وقادرة على اللحاق بالركب في بحال التنمية وفي آن واحد قادرة على القضاء على الجهل والفقر. مفهوم الشخصية في التربية الإسلامية هو مطابق للتعاليم الإسلامية، والتي لا يمكن فصلهما لأن كلامنهمامترابطتان.

تنمية الشخصية في التربية الإسلامية بحاجة إلى بعض

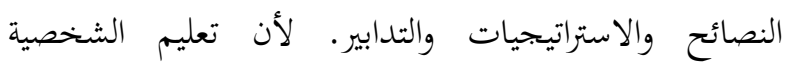

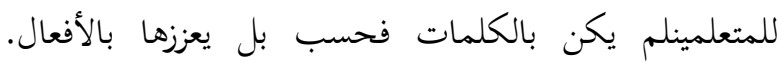

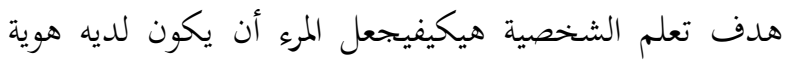
لكل تصرفاته على أساس الهوية الإسلامية.

طوال هذه الفترة كان التعليم لا يزال يفتقر إلى الحد

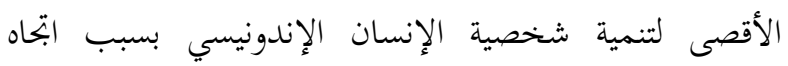

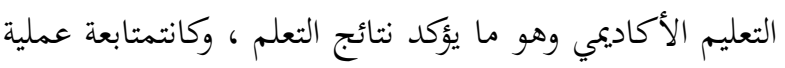


التعلموأهدافهاهي النتائجالأكاديميةوليست المواقف والعقلية والسلوكية المحمودة.

في السنوات الأخيرة حالات الفساد الماليأخذت في الازدياد، وكان بعض النخبة السياسيةيرتكبون الفاحشة، ومشاهدة

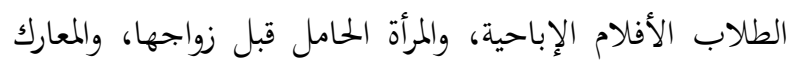
بين الطلاب، وكثير من الحالات التي تتعارض مع الشخصية الإسلامية. ومن المفارقات، فإن هذه الأفعال قد يرتكبها

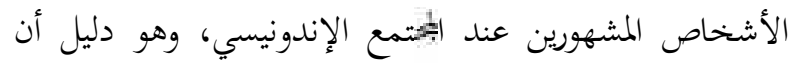

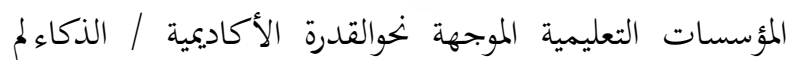

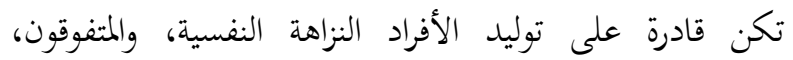
والموثوقون، والأفراد الصادقونولهم المسؤولية، على الرغم من أن مرتكبي تلك الأفعال قد تعلموا العلوم الإسلامية ومن المنظمات

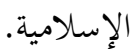

التربية التي تتوجه نهو التثقيف المضض سوف تجعل "ابخرمين المثقفين" فقدان حساسية على أنفسهموغير قادر علحل المشاكل المتنوعة التي تصيب المتعلمين. إن تخصيص جانب الذكاء دون الشخصية القوية سوف يحملهم إلى ميدان

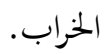

الغرض من التعليم في هذا السياق ليس سوى لتكوين

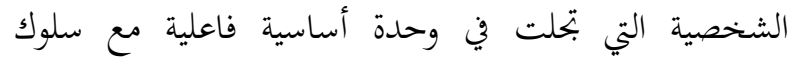
ومواقف من حياثَا. الشخصية هيالكائنة التى تأهل الشخص. أصبحتالشخصية هوية التي تغلب على التجارب المختملة التي تتغير دائما

وفي القرأن الكريم ينقسم نوع شخصية الإنسان إلى ثلاثة أقسام

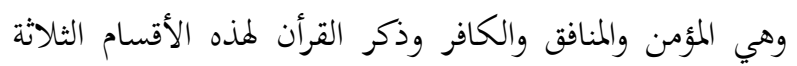

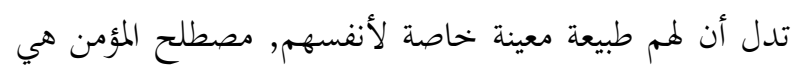
عبارة عن الفرد الناضج (من ناحية النفسية والقلبية والعقلية) للتعامل مع الأخرين وأن علاقته بربه قوية
وكان نزول القرآن لأسباب اضطراب الأمةكما ذكره

بامبانج كيو- أنيس وأدانغ الحنبلي. An هن Anees dan Adang Hambali, 2011) الاضطراب نزل القرآن الكريم ليهدي الناس إلى صراط مستقيم, ومن هذا السبب أرسل الله خحاتم الرسل صلى الله عليه وسلم

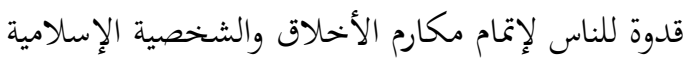

ومن هذا الانطلاق نرى أن القرآن الكريم والرسول صلى الله عليه وسلم لمما دور عظيم في تربية شخصية المسلمين, وطريقة أولية في تعلم الشخصية والأخلاق التي مارسها النبي صلى الله عليه وسلم هي القدوة والتعود, واستمرتطويرها في التربية الإسلامية حتى الآنمن خلال القدوة والتعود ويتحقق ما يريد تقديمها لأن هناك القدوة المتبعة والتعود في ممارستها كان النبي صلى الله عليه وسلم مرب وقدوة للناسوقد بنح عند حياته أن يحل مشاكل الأخلاق التي توجه أمته وبجح

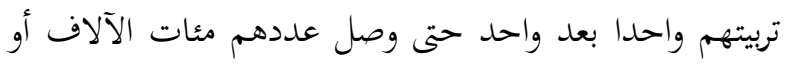

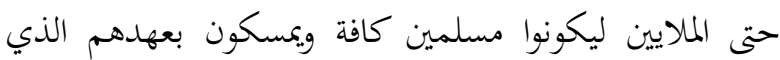
عاهدهم النبي صلى الله عليه وسلم وليس خلقه اختلاق بشري لماين

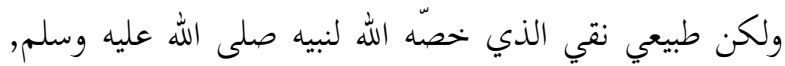
وإذا مشى على الأرض, مشى هونا, وإذا خاطبه أحد قال

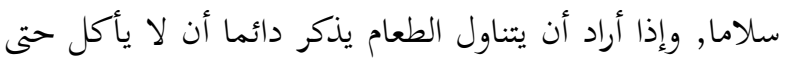
يجوع وإذا أكل لا يشبع, وأنه صلى الله عليه وسلم ينصح أمته أن لا يكونوا من الطامعين. وهذا من هدي النبي صلى الله عليه وسلم أن يكون لأمته شخصية قوية وسليمة.

$$
\begin{aligned}
& \text { يستخدم ثَج القدوة كتعليم الفرد على القيم } \\
& \text { الشخصية عن طريق التعليم الرسمي وغير الرسمي. ومن خلال }
\end{aligned}
$$

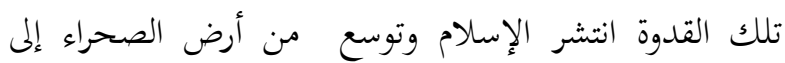


للإسلام دورا كبيراوتأثيرابالغا وتقديرافي بحال البحث والدراسة التي لا ثاية لما عند دول أخرى, وهذه اللحظة التاريخية كأثا

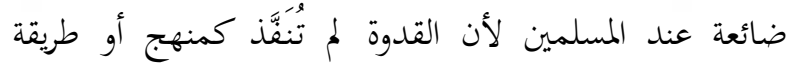
لتبليغ التعاليم الإسلامية في الجمتمع التعددي الحالي.

ومسن المفـترض أن يكــون المعلمـون قـدوة للطـلاب ولكنهم أحيانـا يتصـرفون بتصرفات غـير محمودة فـالمعلم عند التربية الإسلامية هو مرب وقدوة حسنة في كل الأمور إما كان في بيئة المدرسة أم في وسط اليختمع.

كما قدم الإسلام زراعة ثَج الأخهاق المممودة لغرس

القيم الشخصية التي تعتبر أن تكون مقبولة, مستوعبةوممارسـة الإسة

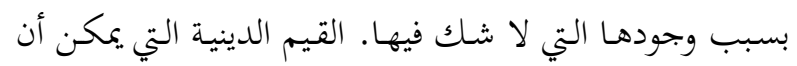

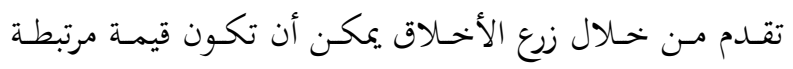

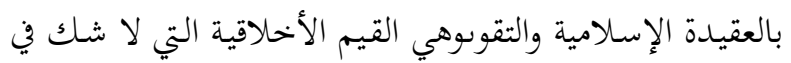
وجودها. هذا النهج يمكن استخدامه من قبل المعلم من خلال

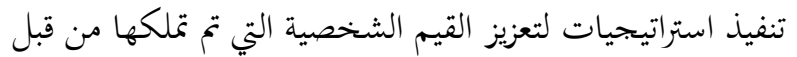
المتعلمين, فتعزيز القيم الشخصية المنبعثة من الدين التي يمتلكها لنعيا

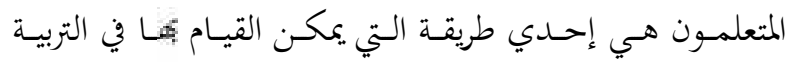

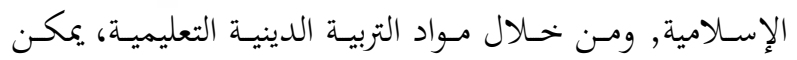
للمعلم عقد التعزيزات التي تستهدف شخصية كل المتعلمين. وبالتالي، فمن الواضح أن في القرآن الكريم هناك

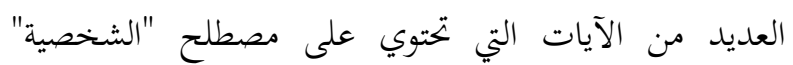
ومشتقاته، مثل تكوينوتنمية شخصية الإنسان، والعوامل التي تؤثر عليها، ثم كيفية التعامل معها, وفي نظر الإسلام فالمسلمون

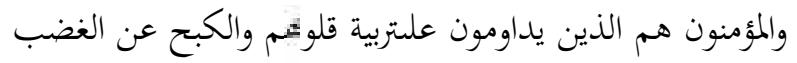
(الصبر)، والتوكل على الله, وإعطاء الصدقة،والنشيط في العبادة, ولا يرتكبون السيئات والحفظ على سلوكهم وتصرفاتم التي تميل ولثي

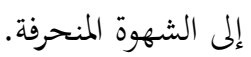

من وصف مفهوم سابق للتربية الإسلامية حول الشخصية، ترى الكاتبة، أن هناك أربعة الخصائص الأساسية على الأقل في زرع الشخصية التي تليق بتنميتها, أولا، انتظام الداخل لكل تصرف يتم قياسه بناء على التسلسل الهرمي لئي
للقيم, فقيمة تصبح المبادئ التوجيهية المعيارية لكل تصرف

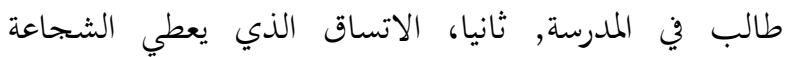
للطلاب، ويجعلهم متمسكين بمبدئهم، ولا يترخون منالمواقف الجديدة أو يخافون من المخاطر, الاتساق هو الأساس لبناءثقة بينهم, وغياب الاتساق تقويض لمصداقية الطلاب. ثالثا, الحكم الذاتي. فهناك استيعاب الطلاب على النظام الخارجي ليكون

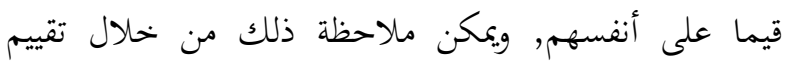
القرارات الشخصية دون تأثر أو ضغط من أطراف أخرى, رابعا،

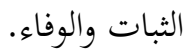

فالمشكلة التي تنبع من الأساس المعري،، هي ما ملائمة تنفيذتعليم الشخصية في سياق حياة الطالب؟ بهذانحتاج إلبإعادة الإعمارونسهم في تحقيق النموذج العلمي في التربية الإسلامية، وفي رأبي، فإن تربية الشخصية في سياق التعليم في إندونيسيا قد بتسدت إلى مسارين: الرسمية وغير الرسمية، ويتم تنفيذها في أنشطة داخل المناهج الدراسية والأنشطة اللامنهجية. هنا، فتكوين الشخصية القوية خاص قوي يُعتبر الهدف الرئيسي

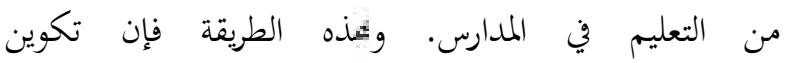
الشخصيةستؤدي إلى تنميتها من خلال الدراسات العلمية التطبيقية لمعالجة مختلف الحقائق التجريبية التي تعني وجود إشارة مخالفات في البيئة التعليمية، على سبيل المثال، حالة المغازلة بين

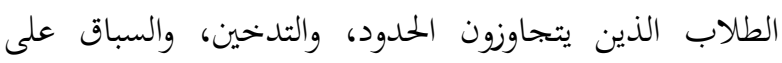
الطريق السريع، لم تكن لديهم النزاهة والالتزام. التحديات التي تواجه التعليم الديني، وخاصة التربية الإسلامية (PAI) في المدرسة، ما هي إلا كيفية تنفيذ تعاليم التربية الإسلاميةولم يكن تعليمهمالدين الإسلامي والقيم الدينية المضة، ولكن أيضا كيفية توجيه الطلاب ليكونوا على استعداد

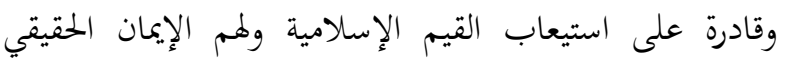
والتقوى وحسن الخلق. التركيز على عملية استيعاب القيم الدينية

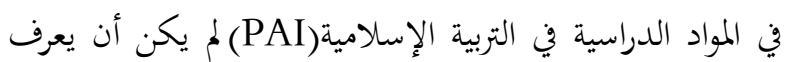
الطلاب مفهوم ونظرية الجوانب التي طُورّت في درس التربية الإسلامية، والحصول على الدرجات الأكاديمية الجيدة مع أثها

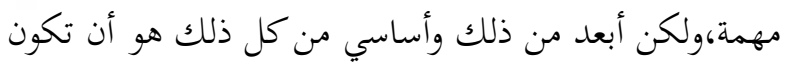


المواد الدراسية في التربية الإسلامية لها دور في الوقاية من

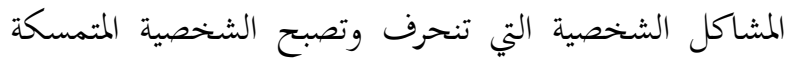
بالقيم الدينية. وهذه تتطلب الاستراتيجية الخاصة من قبل المعلمين، تتطلب إلى الاستراتيجية الخاصةمن قبل المعلمين، بالإضافة إلى الإبداع المؤهل.

وفيما يتعلق بمادة التعليمفإن التربية الإسلامية هي

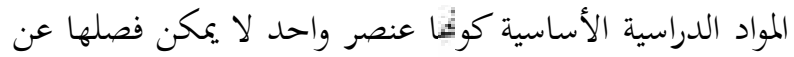
غيرها من المواد الدراسية في كل من المدارس العامة وخحاصة المدارس الإسلامية، التيتهدف إلى تكوين وتنمية شخصية

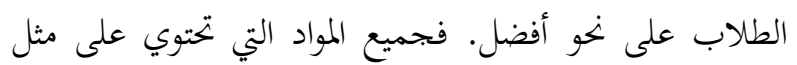
هذه الأغراض تتماشى وتتوافق مع الأهداف التي يمكن أن إنى تحققها المواد الدراسية في التربية الإسلامية، ويمكن أن تكون

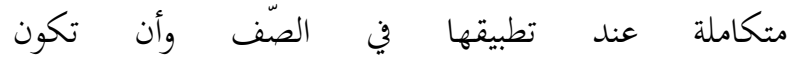
مخططةومنهجةبشكل أفضلمع أهداف وغايات واضحة.

\section{إن وجودمواد التربية الإسلامية التدريسية تُّدف إلى}

الختام

تكوين الطلاب المؤمنين والمتقين لله تعالى، وتحسين خلقهم (الأخلاق الفاضلة)، ولهم المعارف والاستيعاب للقيم الإسلامية. ومهذافإن مواد التربية الإسلامية التدريسية لا تقدّم

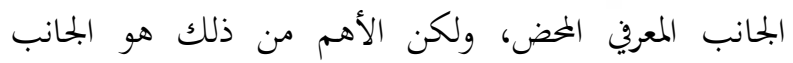

$$
\text { التأثيري أو جانب القيمالتعليمية }
$$

ومهذا، فإن مواد التربية الإسلامية التدريسية في

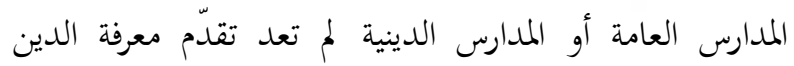
فحسب ولكنهاتكوينوتربيةالطلابأن تكون لمم شخصية قوية، ولهم إيمان وتقوى لمواجهة واقع الحياة المليئة بالتحديات. وبزادهم الشخصية القوية تكون أيامهم مزينةبالأخلاق الفاضلة أينما كانوا، ومهما كان حال عملهم.

ولهذا فإن الأشياء العاجلة حاليالتي يجب أن ينفذهامعلمو التربية الإسلامية ما هي إلا جهودهم لتطوير
الاستراتيجيات وطرق التدريس التي يمكن أن توسع مفاهيم

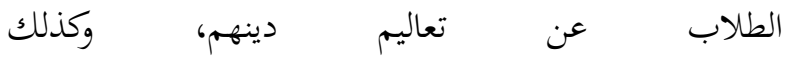
تشجيعهملاستيعابهاوممارستها في حياثم اليومية، وكذلك إنشاء الأخلاق الفاضلة وشخصية قوية كهويتهم.

المبادئ الأساسية التعليمية في التربية الإسلامية في

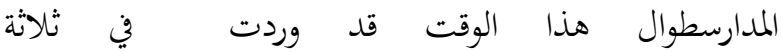
الإطاراتالأساسيةللإسلام، وهي العقيدة، والشريعة والأخلاق.

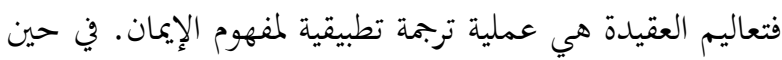

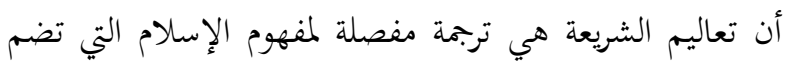

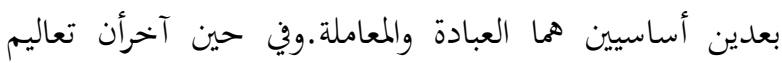

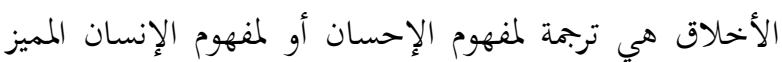
والكامل على مخلوقات الله الأخرى.

تطورت تلك المبادئ الأساسية الثلاثة إلى جوانب مختلفة من الدراسات الإسلامية مثل جانب القرآن والفقه،

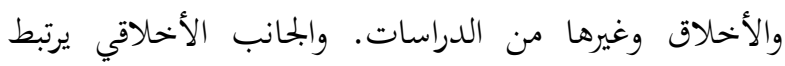
مباشرة إلى تكوين وعي الشخصية من المؤمنين.

ولتعليم شخصية الطلاب، فإنه لا يكون كافيا من خلال المواد التعليمية في الفصل الدراسي فحسب. ويمكن نعليم

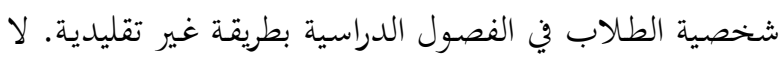
توجـد هنـاك طريقـة أفضـل مثـل طريقـة قـدوة في سياق تقــيم وتكوين شخصية الطلاب المسلمين.

تسـتخدم ثــج القـدوة لتعلـيم القـيم الشخصـية مـن

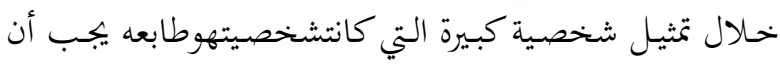
تحاكي حتى يتم تدريسها ليست بحردة كلام فارغ (خدمة حي).

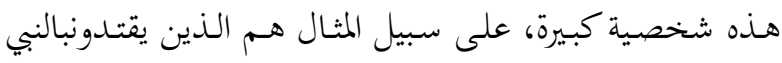

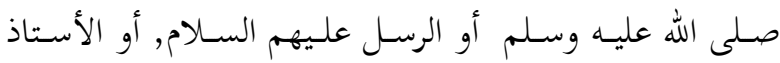
والوالدين والقادة في بحتمع ما أو العلماء.

كاننهج القدوة مهمأن يواصلبنهج التعود. هذا النهج استخدمه المعلمون من خحلال تنفيذ الاستراتيجيات النموذجية 
(النمذجــة) وظهـر التعـود في المواقـف والسـلوك المحمـود. يـتم

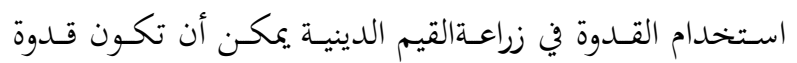

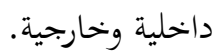

فالقــوة الداخليـة، علـى سـبيل المثــال، هــو المعلـمـ

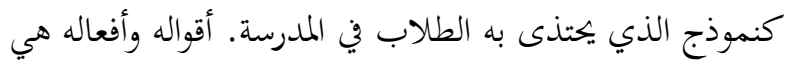

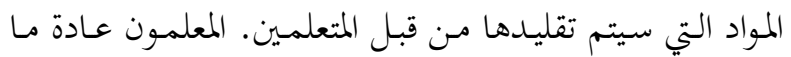

يعطونويظهرونالقدوة مباشرة في مختلف الأمور والأنشطة، سواء

في البيئة المدرسية، مثل: أن يدعو الله عند بداية الدراسةوفهايتها،

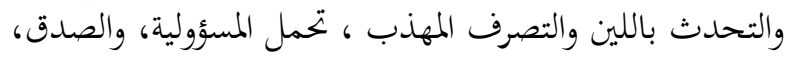

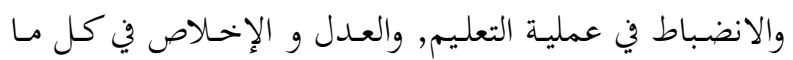

يفعل، وكذلك خارج البيئة المدرسية (البمتمع).

القدوة من الخارج يمكن أن يتم من خلال تقديم أمثلة

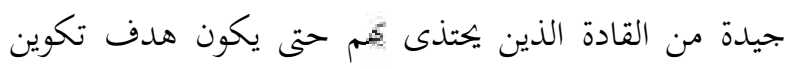

$$
\text { الشخصية وتربيتها يمكن تحقيقه. }
$$

\section{REFERENCES}

Al-Ghazali. (2008). Mutiara Ihya' Ulumuddin. Terj. Irwan Kurniawan Bandung: Mizan.

Al-Rasyidin. (2012). Falsafah Pendidikan Islami: Membangun Kerangka Ontology, Epistemology, Dan Aksiologi Praktik Pendidikan. Cet. III. Jakarta: Citapustaka Media Printis.
Chalplin, J. P. (2011). Kamus Lengkap Psikologi. Terj. Kartono, K. Jakarta: Rajawali Press

Departemen Pendidikan dan Kebudayaan. (2003). Kamus Besar Bahasa Indonesia Edisi III. Jakarta: Balai Pustaka. cet, ke-3.

Goleman, D. (1996). Kecerdasan Emosional. Terj. Hermaya, T. Jakarta: Gramedia Pustaka Utama.

Howard, S. F. \& Miriam, W. S. (2006). Kepribadian, Teori Klasik Dan Riset Modern. Terj. Fransiska Dian Ikarini. Jakarta: Erlangga.

Jalaludin. (2001). Teologi Pendidikan. Jakarta: PT Raja Grapindon Persona

Mulyasa, E. (2013). Pengembangan dan Implementasi Kurikulum 2013. Bandung: Remaja Rosdakarya.

Q-Anees, B. \& Hambali, A. (2011). Pendidikan Karakter Berbasis AlQur'an. Bandung: Simbiosa Rekatama Media. cet. ke-3.

Sobur, A. (2003). Psikologi Umum Dalam Lintasan Sejarah. Bandung: Pustaka Setia. 